OPEN ACCESS

Edited by:

Casper H. A. Van Leeuwen, Netherlands Institute of Ecology (NIOO-KNAW), Netherlands

Reviewed by:

Ove Eriksson

Stockholm University, Sweden

Kim McConkey,

National Institute of Advanced

Studies, India

*Correspondence:

Aarón González-Castro

arongcastro@gmail.com

Specialty section:

This article was submitted to Biogeography and Macroecology,

a section of the journal

Frontiers in Ecology and Evolution

Received: 27 September 2018 Accepted: 01 February 2019

Published: 20 February 2019

Citation:

González-Castro A, Pérez-Pérez D,

Romero J and Nogales M (2019)

Unraveling the Seed Dispersal System

of an Insular "Ghost" Dragon Tree

(Dracaena draco) in the Wild.

Front. Ecol. Evol. 7:39.

doi: 10.3389/fevo.2019.00039

\section{Unraveling the Seed Dispersal System of an Insular "Ghost" Dragon Tree (Dracaena draco) in the Wild}

\author{
Aarón González-Castro ${ }^{1,2 *}$, David Pérez-Pérez ${ }^{1}$, Javier Romero ${ }^{1}$ and Manuel Nogales ${ }^{1}$ \\ ${ }^{1}$ Island Ecology and Evolution Research Group (CSIC-IPNA), La Laguna, Spain, ${ }^{2}$ Canary Islands' Ornithology and Natural \\ History Group (GOHNIC), Buenavista del Norte, Spain
}

Despite being abundant in urban gardens, the Canary Islands dragon tree Dracaena draco is close to extinction in the wild. It tends to produce relatively large fruits, which limits the pool of vertebrates that might disperse its seeds. We aimed to shed light on the seed dispersal system of this plant by studying its fruit size in relation to the feeding behavior of its present dispersers, and to discuss on possible differences with the past dispersal system, when large-sized dispersers were abundant. Besides fruit and seed characterization, we performed experiments on seedling emergence (using the characterized seeds), and field observations of the fruit handling behavior of frugivorous birds. Seed removal by granivores beneath and outside the dragon tree canopies was assessed through a field experiment. An additional seedling emergence experiment tested the effect of pulp removal from around the seed (using seeds contained within the fruits and manually depulped seeds). A feeding experiment was carried out with captive individuals of the Canary endemic white-tailed pigeon Columba junoniae-a large frugivore that occasionally consumes $D$. draco fruits - to test if its gut treatment influences seed viability. Small fruits produced seeds unable to germinate, while most seedling emergence was recorded only for seeds from large fruits. Our observations suggest that the only passerine species able to swallow large fruits is the medium-size passerine Turdus merula, whereas small passerines tended to pluck the pulp without aiding seed dispersal. Nonetheless, Sylvia atricapilla - the largest among the group of small passerines-occasionally transported fruits away from parent plants to consume the pulp, resulting in seed dispersal without any digestive treatment. This behavior indicates $S$. atricapilla might be occasionally a legitimate disperser of $D$. draco, since our experiments suggest that seed transport away from parent trees and pulp removal enhance both post-dispersal seed survival and seedling emergence. Lastly, the pigeons used in the experiment regurgitated mostly viable seeds, suggesting the legitimacy of $C$. junoniae as seed disperser for $D$. draco. Therefore, although $D$. draco likely had more seed dispersers in the past, we identified at least two bird species that can still disperse its seeds nowadays.

Keywords: frugivorous birds, fruit size, legitimate seed dispersal, seed traits, seed predation, seedling emergence 


\section{INTRODUCTION}

Frugivory and seed dispersal is a crucial stage in the reproductive cycle of many fleshy-fruited plants because it allows them to colonize new territories, increase gene flow (Nathan, 2006) and move away from parent plants. These benefits also avoid competition and reduce exposure to natural enemies (Janzen, 1970; Connell, 1971). However, many plant species are currently facing an overwhelming loss of their seed dispersers due to factors like hunting and habitat destruction (e.g., Tilman et al., 1994; Sekercioglu et al., 2004; Tylianakis et al., 2008). Nonetheless, the dispersal service provided by an animal species may cease due to a decline in its population, before it becomes totally extinct (McConkey and Drake, 2006; McConkey and O'Farrill, 2016).

Loss of disperser animals has important demographic and evolutionary consequences for plants (Tilman et al., 1994; Traveset and Riera, 2005; Guimarães et al., 2008; Galetti et al., 2013; Säterberg et al., 2013; Pérez-Méndez et al., 2015, 2018). These consequences are especially important in isolated systems-like those on oceanic islands-because plant-disperser mutualisms may be more symmetric there (González-Castro et al., 2012) or plants might rely on just a few animals providing dispersal services (Schleuning et al., 2014). Also, it is worth remembering that although a plant species can still be dispersed by animals after the loss or decline of its main dispersers, its natural regeneration and demography can be compromised by the low efficiency of the remaining dispersers, leading to a suboptimal dispersal system (Valido, 1999; Cordeiro and Howe, 2002; Traveset and Riera, 2005; Pérez-Méndez et al., 2018). Therefore, it is important to know how and to what extent current seed dispersal systems may help threatened plant species to buffer the loss or decline of their main dispersal agents.

The fauna of the Canary archipelago has undergone a severe decline in large-sized frugivorous animals, like giant endemic lizards (Gallotia spp.) and birds like pigeons (Columba bollii, and $C$. junoniae), which might affect the natural regeneration and demography of plant species producing large-sized fruits (Hansen and Galetti, 2009; Wotton and Kelly, 2011; PérezMéndez et al., 2015). For instance, the maximum snout-vent length (SVL) of giant lizards in the past was $502 \mathrm{~mm}$ for the extinct G. goliath, whereas for G. stehlini, endemic to Gran Canaria, it is currently $280 \mathrm{~mm}$ (Pérez-Méndez et al., 2015). Nonetheless, it is also important to highlight that on the other islands, there are no giant lizards or their surviving natural populations are now restricted to small areas on isolated cliffs. Therefore, the largest non-giant lizard that could play a significant role as disperser of large-fruited plants on those islands is G. galloti, with a maximum SVL of $145 \mathrm{~mm}$ (PérezMéndez et al., 2015). In this contribution, we tried to shed light on the structure and functioning of the current seed dispersal system of the Canary Islands dragon tree Dracaena draco (Asparagaceae). It normally produces relatively large fruits, for which many frugivorous birds have size restrictions that prevent them acting as legitimate seed dispersers.

Specifically, this study pursued four main goals, to assess: (1) whether fruit size can affect seed traits, seedling emergence and growth, (2) how frugivorous birds of different sizes interact with fruits of D. draco, (3) if fruit carriage away from parent trees and pulp consumption by birds can have significant effects on seedling recruitment, and (4) the potential role of the white-tailed laurel pigeon C. junoniae as legitimate disperser of this tree.

Matching fruit size and gape width is a key factor determining the type of frugivory interaction (Wheelwright, 1985; Rey et al., 1997; Jordano and Schupp, 2000). Therefore, we expected that medium-sized passerines would swallow entire fruits containing seeds, hence acting as legitimate seed dispersers. On the other hand, small passerines, unable to swallow fruits whole, would act as pulp consumers without seed dispersal. Only small passerines able to carry fruits and consume them away from parent trees can be considered as occasional seed dispersers, but without any digestive treatment (Figure 1).

Such pulp consumers would be legitimate dispersers if the following needs are met: (1) pulp removal enhances seed germination (Samuels and Levey, 2005), and/or (2) seed predation is lower away from parent trees than beneath them (Janzen, 1970). However, the effect of pulp on seed germination is highly species-dependent (Robertson et al., 2006), and the vulnerability of $D$. draco to post-dispersal seed predators is unknown. Given the foregoing, we had no a priori expectations in this regard.

Lastly, the white-tailed laurel pigeon $C$. junoniae has been recorded as fruit consumer for D. draco (A. Valido, pers. comm.). However, both species (especially the plant) have become extremely rare in nature and their mutual interaction is difficult to observe (i.e., virtually extinct). For this reason, we performed a captivity experiment to find out if this pigeon's gut treatment has no detrimental effect on $D$. draco seeds, as would be expected for a legitimate disperser (see similar island-plant experiments in Culliney et al., 2012 for Corvus hawaiiensis, extinct in the wild).

\section{MATERIALS AND METHODS}

\section{Natural History and Frugivory on Dracaena draco}

Dracaena draco is a monocot tree endemic to Macaronesia and currently inhabits Madeira, the Canary Islands, Cape Verde and parts of North Africa (Marrero et al., 1998). In the case of the Canaries, this plant species was formerly well-distributed throughout the thermosclerophyllous woodland (100-700 m a.s.l.), along with Canary palm (Phoenix canariensis), Wild olive (Olea cerasiformis), Mastic trees (Pistacia spp.), etc (Fernández-Palacios et al., 2008). However, after colonization and settlement by pre-hispanic inhabitants and Europeans, both that vegetation habitat and $D$. draco have undergone an overwhelming decline, particularly on Tenerife. Moreover, its populations have been subject to anthropogenic pressure due to its resin-“dragon's blood"-being highly valued for medicinal and industrial purposes (Santos, 1979). Although this plant species is still cultivated in private and public gardens worldwide, its natural populations on Macaronesian islands are highly fragmented and show very low natural regeneration. This leads 


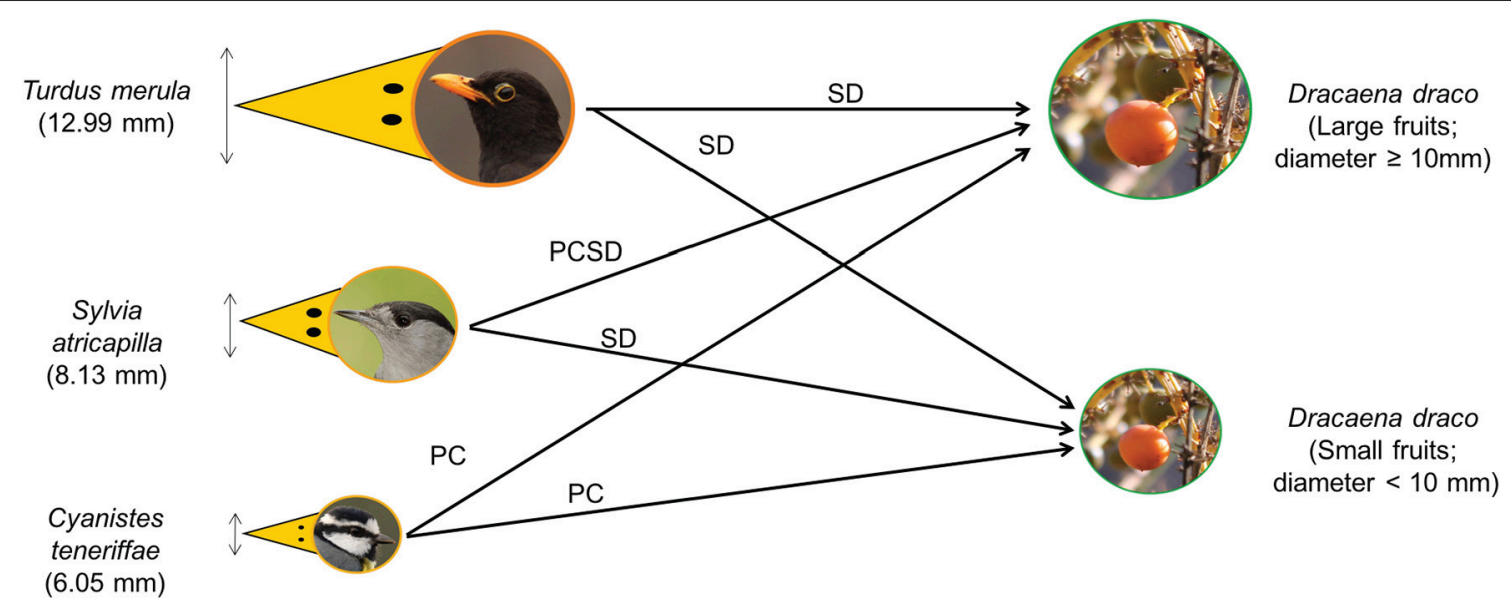

FIGURE 1 | Conceptual framework of our hypothesis. Medium size passerines, such as Turdus merula, can swallow Dracaena draco fruits whole and act as legitimate seed dispersers (SD), regardless of fruit width. Small passerines were expected to act mostly as pulp consumers (PC). Large small passerines (e.g., Sylvia atricapilla) may be able to swallow whole small-width fruits and legitimately disperse the seeds (SD), whereas they will only peck out the pulp of large fruits, acting as pulp consumers (PC). Nonetheless, small passerines may occasionally be able to transport large fruits to consume the pulp away from parent trees, leading to seed dispersal without digestive treatment (PCSD). For each bird, its mean beak gape width is shown between parentheses (AG-C, unpubl. data). The terms used to define the type of fruit-handling behavior follow Wheelwright (1985) and Jordano and Schupp (2000). Picture credits: birds by Beneharo Rodríguez and D. draco fruit by AG-C.

the species to be listed as "Vulnerable" in the IUCN Red List (2018) and considered a "ghost tree" in the wild.

Fruits of $D$. draco are orange-reddish globose berries, which can reach up to $13.59 \pm 0.85 \mathrm{~mm}$ in diameter (Marrero and Pérez, 2012), whose seeds-between 1 and 3 per fruit-are dispersed by frugivorous animals (endozoochory). That fruit size is too large for most bird species to swallow. Consequently, any study addressing the seed dispersal system of this plant species should consider the variability of its fruit size. Currently, the bird species that have been reported to consume $D$. draco fruits are small passerines: blackcap Sylvia atricapilla and Sardinian warbler S. melanocephala (A. González-Castro unpublished data), the medium-sized passerine Eurasian blackbird Turdus merula (González-Castro et al., 2012), and the white-tailed laurel pigeon Columba junoniae (A. Valido, pers. comm.).

Several seeds of $D$. draco have been also found in feces from the endemic Canary lizard Gallotia galloti (Valido, 1999) and the Gran Canaria giant lizard G. stehlini (González-Castro et al., 2012). However, so far as we know, interactions of $D$. draco fruits with lizards are much less common than interactions with birds. Therefore, from a quantitative perspective, birds seem to play a more important role than lizards in the current seed dispersal system of $D$. draco.

\section{Categorizing Fruit Sizes}

The frugivorous birds that currently consume fruits of $D$. draco can be split into two different functional groups: (1) small birds (encompassing small-sized passerines) and (2) large birds (including the medium-sized passerine T. merula and the pigeon C. junoniae). Consequently, fruits of $D$. draco were categorized according to their width into two different groups: "small" $(<10 \mathrm{~mm})$ and "large" $(\geq 10 \mathrm{~mm})$. This threshold width was considered as the largest fruit that might be entirely swallowed by small passerines based on their beak gape width. Among the small passerines that consume $D$. draco fruits, the largest is $S$. atricapilla, whose gape width is $8.13 \pm 0.72 \mathrm{~mm}$ (mean $\pm \mathrm{SD}$; A. González-Castro, unpubl. data). We selected $10 \mathrm{~mm}$ width instead of $8.13 \mathrm{~mm}$ as a conservative threshold because birds can usually swallow fleshy-fruits slightly wider than expected from their gape width. On the other hand, fruits considered "large" would only be swallowed by medium-sized passerines and frugivorous pigeons.

\section{Fruit-Seed-Seedling Relationships}

To evaluate the relationship of fruit size with seed biometric features (diameter and weight) and seedling performance (emergence and growth), a total of 238 fruits were randomly collected from 11 parent plants (Table 1) located on the islands of Tenerife (individuals nos. 1-10, in the municipalities of La Laguna and Tegueste) and Gran Canaria (individual no. 11, in the municipality of Gáldar). Fruits were collected in September 2017, and the number of fruits and parent trees was constrained by their availability at time of collection. The fruits from each individual plant were stored separately to keep the source of seeds identified, allowing us to account for the mother tree effect.

The length and width of each fruit were measured. Based on the width, fruits were classified as "small" or "large" as previously explained. We chose to classify fruits into "small" and "large" rather than using the individual fruit width, so as to directly relate our results to what would occur in the wild in the interaction with small passerines (which can swallow only small fruits) or with medium passerines and pigeons (which can swallow both sizes of fruits). For each fruit, the number of seeds, as well as the seed width and weight were recorded. Width of 
TABLE 1 | Summary of fruit width $(\mathrm{mm})$ collected from individual trees.

\begin{tabular}{|c|c|c|c|c|c|}
\hline Plant ID & $n$ & Fruit width (Mean \pm SD) & Fruit width range (Min.-Max.) & Large fruits & Small fruits \\
\hline Plant \#1 & 20 & $(9.55 \pm 1.24)$ & $(7.83-12.10)$ & 7 & 13 \\
\hline Plant \#2 & 20 & $(10.43 \pm 2.19)$ & $(6.98-15.02)$ & 10 & 10 \\
\hline Plant \#3 & 20 & $(10.35 \pm 1.36)$ & $(8.12-12.99)$ & 13 & 7 \\
\hline Plant \#4 & 30 & $(8.73 \pm 1.41)$ & $(6.50-11.61)$ & 8 & 22 \\
\hline Plant \#5 & 25 & $(11.84 \pm 0.48)$ & $(11.03-13.01)$ & 25 & 0 \\
\hline Plant \#6 & 12 & $(11.78 \pm 0.66)$ & $(10.50-12.53)$ & 12 & 0 \\
\hline Plant \#7 & 20 & $(11.73 \pm 0.90)$ & $(10.51-13.14)$ & 20 & 0 \\
\hline Plant \#8 & 31 & $(9.97 \pm 2.24)$ & $(7.25-20.01)$ & 15 & 16 \\
\hline Plant \#9 & 20 & $(10.44 \pm 0.89)$ & $(7.84-11.95)$ & 15 & 5 \\
\hline Plant \#10 & 20 & $(9.55 \pm 0.54)$ & $(8.57-10.32)$ & 6 & 14 \\
\hline Plant \#11 & 20 & $(11.26 \pm 0.66)$ & (10.18-12.76) & 20 & 0 \\
\hline
\end{tabular}

Number of collected fruits $(n)$, the mean $( \pm S D)$ and range (min.-max.) of fruit width, as well as the most common fruit type produced by each.

fruits and seeds were measured with a digital caliper ("Stainless

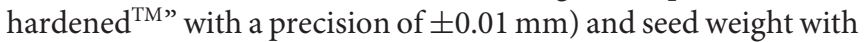
a digital balance ("Cassio Plus METTLER TOLEDO"TM" with a precision of $\pm 0.1 \mathrm{mg}$ ).

A total of 210 measured and weighed seeds were used in a seedling emergence experiment. Seeds were individually sown in multi-pot trays filled with a standard substrate $(50 \%$ peat and 50\% agricultural soil). Trays were placed in a greenhouse and watered every 3 days between October 2017 and March 2018 (inclusive), according to the main rainy period in Canary Islands. The experiment was monitored every 5 days and seedling emergence was recorded when any part of the seedlings was visible. After emergence, seedling length was measured using a digital caliper every 5 days. At the end of the experiment, seedling growth rate was calculated as the difference between the final and the initial length divided by the days elapsed after its emergence.

\section{Frugivory Rate and Fruit-Handling Behavior}

From October 2017 to March 2018, frugivory interactions were recorded at all six fruiting individuals at the study site. Due to the impracticability of access to a high-density natural population of dragon trees, a rural garden with planted individuals was chosen as study site for this purpose. The selected garden was in the municipality of Tacoronte (Tenerife; UTM: 28R $362650 \mathrm{~m}$ E/ $3154947 \mathrm{~m} \mathrm{~N}, 250 \mathrm{~m}$ a.s.l.), away from urban areas and surrounded by natural vegetation of the potential habitat of D. draco (i.e., thermosclerophyllous woodland). With the only exception of $C$. junoniae-whose interaction with dragon tree fruits has been seldom recorded in the wild (A. Valido, pers. comm.) - and Erithacus rubecula, the community of fruit-eating birds recorded at the study site was composed of the same species found in the wild (i.e., S. atricapilla, S. melanocephala, S. conspicillata, T. merula, and Cyanistes teneriffae). The gape width of E. rubecula is smaller than that of S. atricapilla. Therefore, if $E$. rubecula interacts with $D$. draco fruits in the wild, it is expected to act as a small passerine.

Frugivory censuses were performed on 3-5 days per week from 08:00 to 10:00 (local time) until the whole fruit crop was depleted, and a total of $67 \mathrm{~h}$ of observations were accumulated. We used binoculars at some distance from observed trees in order to not interfere with the normal activity of birds. Each census of each individual plant lasted for $15 \mathrm{~min}$, and after each census, the next targeted plant was selected at random. During each census, we recorded the number of visits made by each type of frugivore (i.e., small and medium-sized passerines at species level) and the type of interaction, such as: pulp consumption (with no dispersal), fruit swallowing (which implies internal seed dispersal), and carriage of fruit away from the parent tree (which implies seed dispersal but without any digestive treatment).

We are aware of the need for frugivory censuses at wild trees. However, the last fruiting season was characterized by low fruit production. For this reason, in this study we have also included additional censuses performed from October 2010 to December 2010. These used the same methodology on two solitary individual plants growing in natural conditions: One in Bandama (UTM: 28R $455165 \mathrm{~m} \mathrm{E/} 3100775 \mathrm{~m} \mathrm{~N}, 235 \mathrm{~m}$ a.s.l.) and the other in El Palomar (UTM: 28R $454278 \mathrm{~m}$ E/ $3104512 \mathrm{~m}$ $\mathrm{N}, 250 \mathrm{~m}$ a.s.l.), both on Gran Canaria. With these censuses, we reached up to 7.92 additional hours of observations. However, these additional censuses lasted for a variable time (from 10 to $45 \mathrm{~min}$ ). Therefore, to make all censuses comparable, the number of visits by birds was standardized by dividing it by the time in minutes the targeted plant was observed during each census. The goal of this part of the study was to record fruit handling by birds, and both observational periods (for Tenerife and for Gran Canaria, respectively) coincided with the natural fruiting phenology of $D$. draco. Also, during both periods, frugivory interactions were recorded for the same bird species (all of them resident in the Canary Islands). Therefore, the information recorded about fruit handling by birds is unlikely to be affected by censuses performed during two different periods.

\section{Consequences of Occasional Dispersal With No Digestive Treatment by Small Passerines \\ Effect of Pulp Removal on Seedling Emergence}

To test for the effect of pulp removal on the percentage and rate of seedling emergence, we performed a seedling emergence experiment. We sowed 496 seeds/fruits randomly collected from 
13 parent trees: the 11 mentioned above (see the section "Fruitseed-seedling relationships") plus another two parent trees located on Tenerife, whose fruits were also collected in September 2017. These emergence trials were carried out following the same protocol as above, to test the effect of seed size and weight on seedling emergence and growth. However, in this case, we only recorded the seedling emergence date.

This emergence experiment applied two treatments: the first consisted of 371 seeds whose pulp was manually removed (named "depulped" treatment), whereas the second treatment, named "with pulp," consisted of 125 entire fruits containing the seed(s) inside. Although most fruits contain one seed, some have two (more rarely three). For this reason, to be cautious regarding the differences in emergence time between treatments, we considered only the first seedling that emerged. Nonetheless, we never recorded more than one emerged seedling in pots where entire fruits were sown, so this precaution was no longer necessary.

\section{Seed Removal Beneath and Outside the Canopy of Parent Trees}

If pulp consumption occurs at the fruiting tree, the seeds contained within fruits fall beneath parent trees. However, if the pulp consumer transports fruits before consuming them, the contained seeds are dispersed to areas away from parent trees. To assess if fruit carriage away from parent trees can help to reduce the probability of seed removal with respect to seeds falling beneath parent trees, we performed a post-frugivory seed removal experiment. This assessment was carried out in April, 2018. As replicates, we selected 12 parent trees that had just fruited or we were sure had fruited during the immediately previous fruiting season (i.e., that showed fallen fruits and seeds beneath their canopy).

The seed removal trial consisted of a Petri dish containing the seeds. For each parent tree (i.e., replicate), we set up two different trials with 10 seeds each: one trial beneath the canopy of the plant ("beneath" treatment), and the other at five meters away from the plant canopy ("outside" treatment). The choice of five meters for the "outside" treatment was based on the mean minimal distance that $S$. atricapilla flies from parent trees carrying $D$. draco fruits in its beak (pers. obs.).

These trials were left there for 15 days and were inspected every day and night to ensure they were not disturbed and to record the number of seeds remaining until the end of the experiment. Fifteen days was the minimal time that seedlings took to germinate in our experiment. It allowed us to simulate the time that a seed is naturally exposed to rodents and granivorous birds before germination.

\section{Recreating a "Ghost" Interaction}

Due to the rarity of $D$. draco in the wild and the shy behavior of $C$. junoniae, it is very difficult to record this plant-animal interaction in the wild. Therefore, we performed a captivity experiment in aviaries at the $C$. junoniae breeding center (Gran Canaria). There were seven identical aviaries $(8 \times 4 \times 3 \mathrm{~m})$, each containing a pair of adult pigeons (one male and one female). Therefore, our seven feeding trials included 14 white-tailed laurel pigeons. This center was established for a project to reintroduce this pigeon on the island, and welfare of the animals is its priority. Therefore, access to aviaries was limited to once a week, which determined the frequency of offering fleshy-fruits of $D$. draco and collecting regurgitated/defecated seeds.

In addition to fleshy-fruits included in the feeding trials, all pigeons were maintained on a granivore diet composed of a commercial mixture of seeds (used to feed domestic pigeons, C. livia), complemented with freshly-cut branches of two Fabaceae plant species (Chamaecytisus proliferus and Bituminaria bituminosa). To facilitate treatment of seeds in the gizzard, birds had grit and water available ad libitum. Although the pigeons at the breeding center do not receive native fruits as part of their regular diet, all had been exposed to some species of native fruits occasionally as supplementary diet enrichment items.

In each of the seven trials, a total of 210 fruits from seven $D$. draco parent plants were offered to each pair of pigeons once a week. Fruits were offered naturally attached on the raceme immediately after collection. The foraging behavior of pigeons was observed during the first hour with binoculars from a hide to confirm that pigeons ate the available fruits and the type of interaction (swallowing the entire fruit or plucking the pulp). Fruits were offered for 7 days, and at the end of experiment we collected all these pigeons' regurgitations and defecations to look for $D$. draco seeds. Seeds found were exposed to the triphenyl tetrazolium chloride (TTC) test to check their viability, following the protocol described in Marrero et al. (2007). Whereas, most seeds required $48 \mathrm{~h}$ of incubation in tetrazolium, we left them for $96 \mathrm{~h}$ due to the low cell-permeability of $D$. draco embryos. As control group, we repeated this process with 30 manually depulped seeds from the same parent plants.

\section{Statistical Analyses}

We performed a Generalized Linear Mixed Effect Model (GLMM) with a Poisson error distribution to test if the two types of fruits (large and small) had different numbers of seeds. To test if seed weight and width differed between types of fruits, a GLMM with a normal error distribution was used. To compare the percentage of emerged seedlings between large and small fruits, we used a GLMM with a binomial error distribution. In all GLMMs, the parent tree from which fruits were collected was included as a random effect factor.

To test if the seed weight and width influenced the vigor of emerged seedlings, we first performed a Principal Component Analysis (PCA) with both seed weight and width. The first component was a linear combination of seed weight and width, which accounted for $99.7 \%$ of the variance in seed biometry. Its loadings were used to create a predictor variable called "seed size." The growth rate was used as response variable in a linear regression.

To assess if the frugivory interaction rate was different between the two types of dispersers (small vs. medium-sized passerines), we performed a GLMM with a normal error distribution where the response variable was the standardized visitation rate (visits per minute of census). The individual plant observed at each census, nested within the census date, 

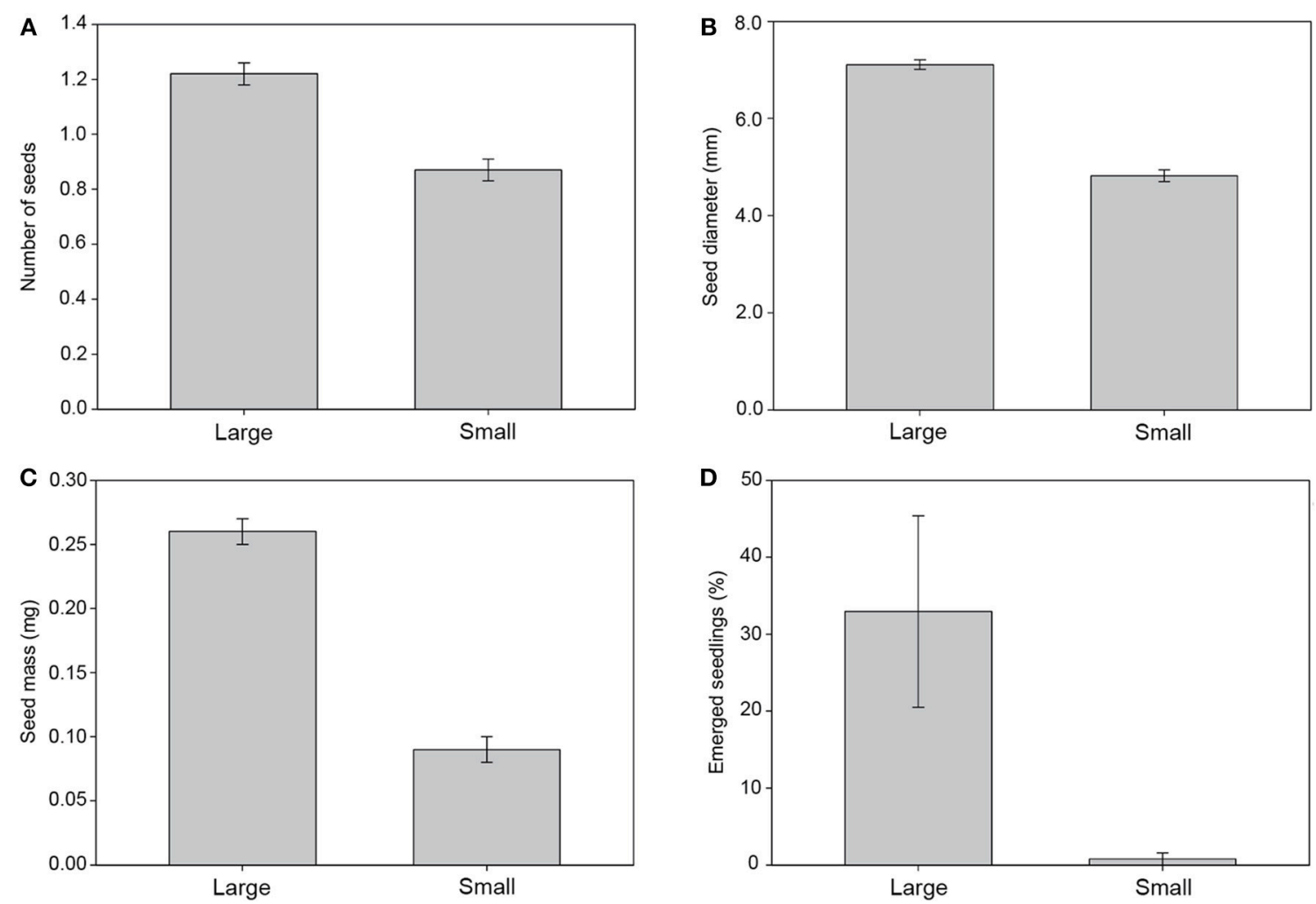

FIGURE 2 | Relationship of fruit type (large vs. small) to the number of seeds it contained (A), seed width (B), seed mass (C), and seedling emergence success (D).

was set as a random effect factor to account for pseudoreplication. To avoid zero inflation, all 15 -min censuses within the same month were pooled. To compare the percentage of legitimate interactions (i.e., frugivory with actual seed dispersal) between the disperser types, we performed a $G$-test (Sokal and Rohlf, 1995).

To compare the percentages of seedlings that emerged from "depulped" seeds and those "with pulp" we performed a GLMM with binomial error distribution and set the parent tree as a random term. In the case of emergence rate, the cumulative number of seedlings that emerged during the experiment was recorded for both "depulped" and "with pulp" treatments. Comparison between treatments was made with a KolmogorovSmirnov test. The relative proportion of seed predation between seeds left beneath fruiting $D$. draco trees and seeds left away from them was tested with a Generalized Linear Model (GLM), with a binomial error distribution. Lastly, to test if ingestion of $D$. draco seeds by the pigeon $C$. junoniae significantly affected the viability of seeds with respect to non-ingested seeds we used a Likelihood Ratio test (i.e., G-test).

\section{RESULTS}

\section{Fruit-Seed-Seedling Relationships}

Only one of the eleven parent trees used for fruit characterization produced a similar number of small and large fruits, whereas the remaining parent trees produced mostly small or large fruits
(Table 1). Large fruits significantly produced more seeds than small fruits $\left(\chi^{2}=5.23 ; d . f .=1 ; P=0.02\right.$; Figure 2A). Regarding seed biometry, large fruits produced significantly larger $\left(\chi^{2}=\right.$ 122.76; d.f. $=1 ; P<0.001)$ and heavier $\left(\chi^{2}=33.60 ;\right.$ d.f. $=1$; $P<0.001$ ) seeds than small fruits (Figures 2B,C, respectively). Moreover, the proportion of seedling emergence was higher for seeds from large fruits than from small fruits $\left(\chi^{2}=8.21 ; d\right.$.f. $=$ $1 ; P=0.004$; Figure 2D). Lastly, the growth rate of seedlings was negatively related with seed size, although this trend was not significant $\left[F_{(1,58)}=0.2 ; P=0.65\right]$.

\section{Frugivory Rate and Fruit-Handling Behavior}

Five bird species and 156 frugivore interactions were observed during the $74.92 \mathrm{~h}$ of censuses. T. merula (the only medium-sized passerine) was by far the most recorded frugivore, encompassing $46.8 \%$ of interactions, followed by Sylvia atricapilla (32.7\%), S. melanocephala (13.5\%), S. conspicillata (3.2\%), and Cyanistes teneriffae (3.9\%), so that "small passerines" represented $53.2 \%$ of the total interactions observed. When the number of interactions was standardized accounting for observation time (Figure 3A), this difference between small and medium-sized passerines remained, but it was not statistically significant $\left(\chi^{2}=0.42\right.$; d.f. $=1 ; P=0.51$ ).

Turdus merula showed a significantly higher proportion of legitimate interactions than small passerines $\left(G_{1}=170.26 ; P\right.$ $<0.001$; Figure 3B). Among small passerines, S. atricapilla interacted with 51 fruits and was the only one able to disperse 


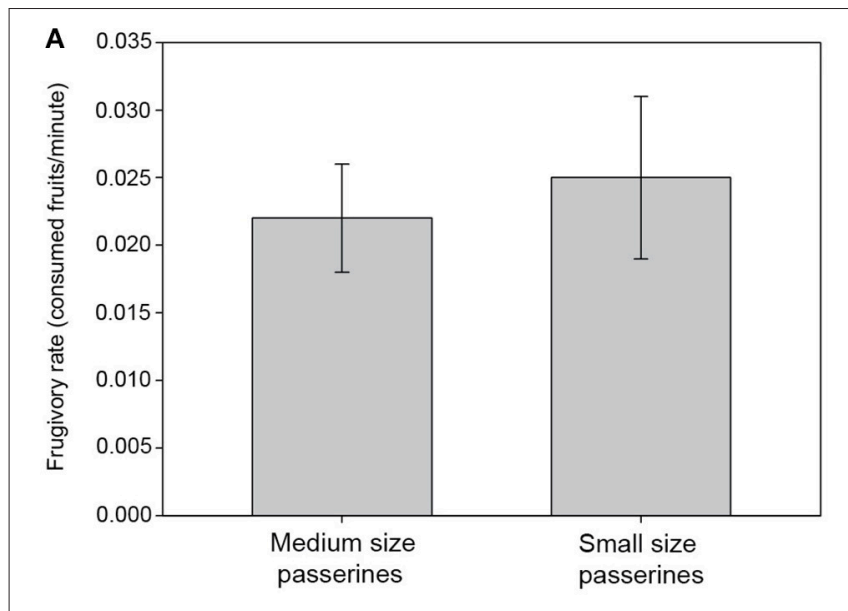

B

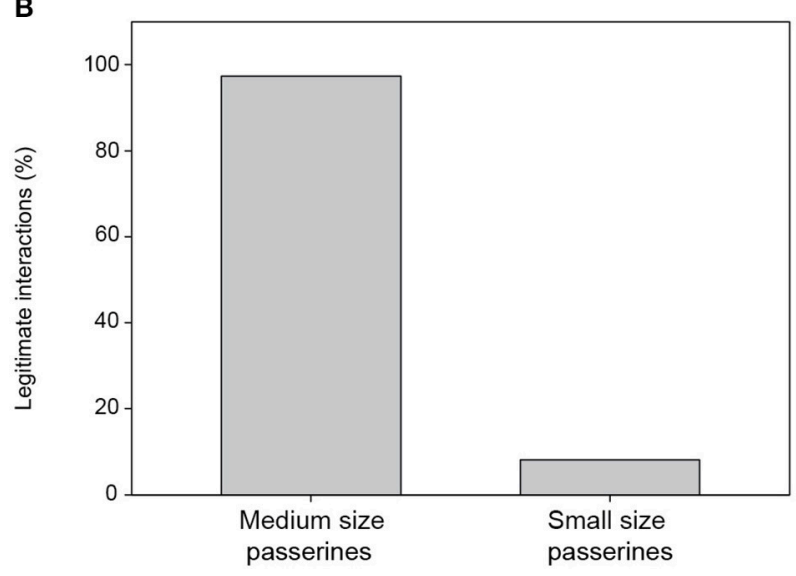

FIGURE 3 | Frugivory interactions involving passerine birds of different sizes were compared regarding interaction rate $(\mathbf{A})$, and their legitimacy as the proportion of interactions leading to actual seed dispersal (B), regardless of whether digestive treatment occurred or not.

D. draco seeds by swallowing a few small fruits $(1.96 \%$ of all its interactions with $D$. draco) or by carrying entire fruits away from parent trees to consume their pulp $(11.8 \%)$. The remaining $86.3 \%$ of its interactions were as pulp consumer at the parent tree.

\section{Consequences of Occasional Dispersal With No Digestive Treatment by Small \\ Passerines}

- Effect of pulp removal on seedling emergence-

The proportion of emerged seedlings (Figure 4A) was significantly higher for depulped seeds than for seeds sown still within the whole fruit $\left(\chi^{2}=20.44 ; d . f .=1 ; P<0.001\right)$. The effect of pulp removal also produced a quicker seedling emergence (Figure 4B) than those seeds sown with pulp $(Z=0.85 ; P<0.001)$.

- Seed removal beneath and outside the canopy of parent trees-

The proportion of seeds damaged or removed by granivores (Figure 4C) was significantly higher beneath the canopy
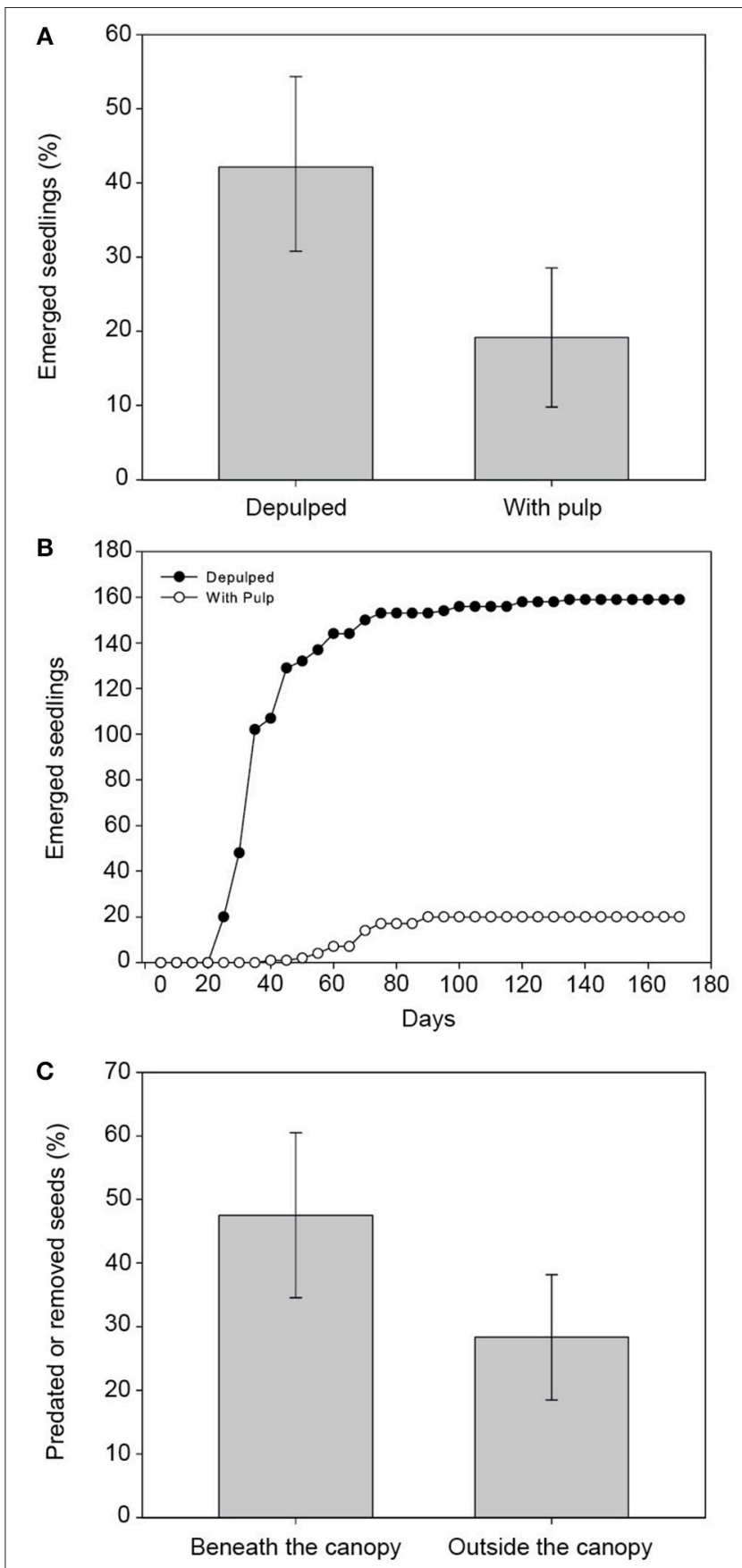

FIGURE 4 | Potential consequences of external seed dispersal for Dracaena draco. Depulped seeds lead to a higher proportion $(\mathbf{A})$ and rate $\mathbf{( B )}$ of seedling emergence than seeds contained inside fruits. Also, seed removal (C) is higher beneath the canopy than outside the canopy of parent trees.

of fruiting $D$. draco trees than outside it $\left(\chi^{2}=9.44\right.$; d.f. $=1 ; P=0.002)$.

\section{Captivity Experiment With Columba junoniae}

During the feeding trial, all observed fruit-pigeon interactions were legitimate, as individuals swallowed the entire fruits. Out 


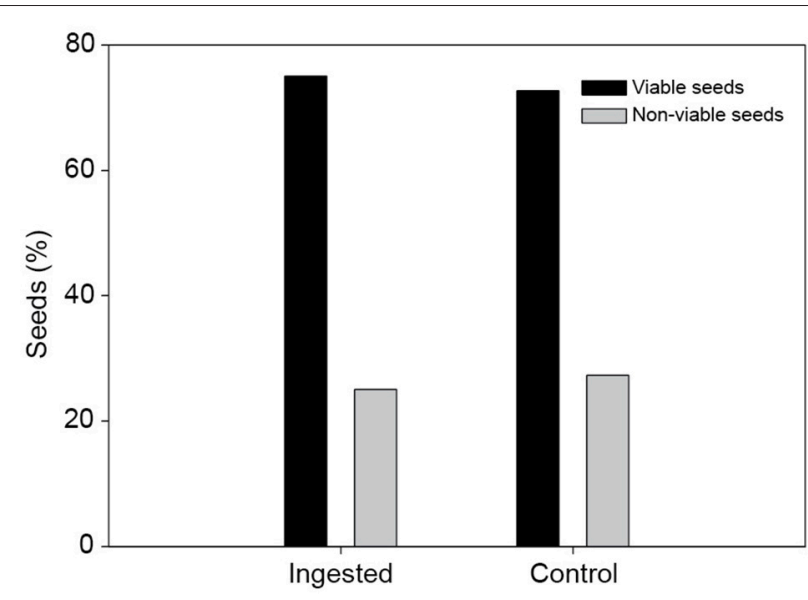

FIGURE 5 | Effect of Columba junoniae gut treatment on Dracaena draco seeds. Ingested and control seeds showed no statistical differences in viability.

of the 210 fruits offered, we recovered 17 seeds that were clearly regurgitated, whereas no seeds were found within feces or bearing fecal traces. Most of the fruits offered were not consumed and had fallen on the ground or were still attached to branches. We found no broken seed fragments in feces or regurgitations. The viability test (Figure 5) showed no significant differences between control seeds and seeds regurgitated by pigeons $\left(G_{1}=0.01 ; P=0.91\right)$.

\section{DISCUSSION}

In this contribution, we have shed light onto intrinsic and extrinsic factors influencing the unknown seed dispersal system of an iconic "ghost" plant in the wild, the Canary Islands dragon tree $D$. draco. Our results show that fruit size is a clear constraint on its successful seed dispersal by birds. Although it is very common in public areas and private gardens, it seems this plant species mostly relies on just one abundant medium-sized passerine (T. merula) and one rare pigeon (C. junoniae) that might be its most important legitimate dispersers. Small passerines mostly acted as pulp consumers but not as seed dispersers. Therefore, given the generalized population decline among large lizards in the Canaries, we found that $D$. draco may still be dispersed by medium and large-sized birds. Its current vulnerability in the wild may be related to other potential problems, like habitat destruction and fragmentation and herbivory by introduced mammals.

\section{Intrinsic Aspects of the Seed Dispersal System of $D$. draco}

Although $D$. draco can produce large and small fruits, most individual trees produced mostly large or small fruits, but rarely both fruit types (Table 1). Furthermore, large fruits produced more and better seeds-in terms of size and emergence capability-than small fruits (Figure 2). This suggests a strong maternal effect on fruit type, and hence on seed quality, for germination and seedling survival (Roach and Wulff, 1987). The low capability of some parent trees to produce viable seeds may be also related to the isolation of many of them, growing in urban gardens, leading to a deficit of natural pollinators to enhance the genetic flow among individuals (Wilcock and Neiland, 2002). Another possible (but not exclusive) reason that might explain the strong maternal effect is that the species could be undergoing a genetic bottle-neck effect (e.g., Gilpin, 1991), caused by its current isolation in urban gardens and/or the great population decline it has suffered in the wild.

Our results agree with previous studies showing a negative relationship between seed size and seedling growth rate, not only among different species but also individuals of the same plant species (Fenner and Thompson, 2005 and references therein). This negative trend might equalize the seedling vigor across individuals because, although seedlings from large-seeded individuals have an initial advantage, such a difference is offset by the quick growth rate of seedlings from small seeds (Fenner and Thompson, 2005). This could enhance survival probability in both shaded and open environments. Slow growth might allow individual plants to survive, taking advantage of endogenous resources until a canopy gap appears, whereas quick growth may help plants in open environments to take advantage from the rainy season and start using exogenous resources (Fenner and Thompson, 2005).

\section{Extrinsic Aspects of the Seed Dispersal System of $D$. draco}

Our study shows that the legitimacy of frugivorous passerines as seed dispersers of $D$. draco is clearly constrained by the birds' gape width relative to fruit size, as demonstrated for other plant-bird interactions (Wheelwright, 1985; Rey et al., 1997; Jordano and Schupp, 2000). Indeed, warblers (Sylvia spp.), which are generally considered as seed dispersers (Herrera, 1995), mostly acted as pulp consumers of $D$. draco fruits in the census. Consequently, only half the interactions led to legitimate seed dispersal, mostly thanks to the medium-sized passerine T. merula and, to a lesser extent, a few legitimate interactions with $S$. atricapilla.

Nonetheless, S. atricapilla swallowing small fruits cannot lead to efficient seed dispersal, due to an already existing intrinsic limitation: small fruits-the only ones that can be swallowed by this small passerine-mostly produced non-viable seeds, unable to germinate (Figure 2D). On the other hand, viable seeds inside large fruits will not be internally dispersed by this passerine, since fruits will be mostly pecked instead of swallowed. This change in fruit handling by $S$. atricapilla (i.e., from seed disperser to pulp predator), depending on individual variations in fruit size seems to be a more general pattern than previously thought. Indeed, it has been demonstrated in other plant species with some intraspecific variability in fruit size (Rey et al., 1997). Therefore, the only way for $S$. atricapilla to be an efficient legitimate seed disperser for $D$. draco involves transporting the fruit outside the cover of the parent tree's canopy, for later pulp consumption. 
Although the transport of large fruits by $S$. atricapilla does not imply digestive treatment, our experimental results suggest a potentially beneficial effect of this small passerine due to pulp removal enhancing seedling emergence (Figures 4A,B). Nonetheless, this effect of pulp removal is highly variable among plant species (Robertson et al., 2006), indeed the effectiveness of $S$. atricapilla as seed disperser when taking fruits away from parent plants will depend on the species under study. With respect to post-dispersal seed removal, granivorous birds able to predate upon large seeds like those of $D$. draco (i.e., Fringilla coelebs) were not recorded at the study site. The granivorous birds seen at the study site (e.g., Serinus canarius and Carduelis cannabina) usually fed upon small seeds of herbaceous plants. Therefore, seed removal detected during the experiment may likely be attributable to rodents (Rattus sp. and Mus musculus).

Although rodents may occasionally act as seed dispersers when storing seeds in caches (Forget and Milleron, 1991; Nyiramana et al., 2011), it has also been shown that seed caching mostly occurs outside tree canopies, whereas seeds under the canopies have a higher probability of being eaten (Muñoz and Bonal, 2011). Our experiment showed that the probability of rodents encountering and removing seeds (Figure 4C) is lower at a distance of five meters than beneath the parent tree. Despite such a short distance, the difference was significant. The reason may be the large uncountable amount of $D$. draco seeds clumped beneath parent trees, whereas at five meters the only available seeds were those used in the experiment. This result agrees with the Janzen-Connell hypothesis (Janzen, 1970; Connell, 1971), which states that the concentration of natural enemies for seeds, and hence seed mortality, is expected to be higher where the concentration of seeds is higher.

Given the foregoing, it seems that $11.8 \%$ of the interactions in which S. atricapilla transported fruits away from parent trees resulted in legitimate dispersal, since this helps seeds escape predation by rodents. Nonetheless, although seed density decreases with the distance from the parent tree (Clark et al., 1999; Nathan and Muller-Landau, 2000), we must point out that the seed dispersal tail is larger than the minimal dispersal distance in determining the density of dispersed seeds. In the case of fruit-eating animals, seed dispersal may be clearly directed to beneath other fruiting trees (Wenny, 2001; Russo and Augspurger, 2004; Carlo et al., 2007). Therefore, fruit carriage away from parent trees may lead to a higher probability of post-dispersal predation on $D$. draco seeds if the fruits are carried to other co-fruiting dragon trees, where probably the density of conspecific seeds will also be high. Nonetheless, during our observations, no $S$. atricapilla individual was recorded carrying fruits from one fruiting dragon tree to another.

Considering the role of $C$. junoniae, our experimental results suggest that this large-sized bird (mean weight \pm SE; 395.86 $\pm 5.60 \mathrm{~g}$, J. Romero. unpubl. data) is likely a legitimate seed disperser of $D$. draco as it swallowed the largest fruits whole, and regurgitated viable seeds in a similar proportion to control seeds (Figure 5). Although we recovered a small number of $D$. draco seeds in the aviaries, no fragments of its seeds were found in feces or regurgitations. This is contrary to what occurred with other large-seeded arboreal species such as Apollonias barbujana or Persea indica, whose seeds were predated. This suggests that the hard seeds of $D$. draco can survive the partial digestive treatment of $C$. junoniae before regurgitation. The small number of recovered seeds may be explained by the fact that the cleaning personnel at the aviaries (who entered more frequently) did not count the large amount of fallen fruits they cleaned away. However, beyond some isolated observations in wild D. draco trees (A. Valido, pers. comm.), its fruits have never been recorded as part of the diet of C. junoniae (see Martín et al., 2000; Marrero, 2009), although they share the same habitat. The lack of records for this interaction is probably caused by the rareness of the tree in the wild and constitutes an example of a virtually extinct interaction due to population decline of both interacting species (McConkey and Drake, 2006; McConkey and O'Farrill, 2016).

Although $D$. draco seeds may currently be dispersed by lizards of the genus Gallotia (Valido, 1999; González-Castro et al., 2012), these plant-lizard interactions do not seem to be very frequent. For example, from more than 190 G. galloti feces collected in the study area located on Tenerife, only one seed of $D$. draco was recovered (unpubl. data), whereas in the Gran Canaria study area only nine seeds were recovered from giant lizard G. stehlini feces (González-Castro et al., 2012). This small difference between G. galloti and G. stehlini may be caused by a gape-width restriction comparable to that observed in this study for birds. Furthermore, it is possible that interactions with lizards-especially giant lizards like the extinct G. goliathwere more frequent in the past, when both the plant and such lizards were more abundant. Indeed, if G. stehlini disperses seeds of $D$. draco, it is likely that other giant lizards did so in the past.

Beyond the loss of large lizards as plausible seed dispersers, another potential recruitment limitation of $D$. draco in the wild might be herbivory upon seedlings and juvenile plants by invasive mammals (goats, sheep, and rabbits). In the field study area, goats and sheep have been observed to seriously affect cultivated individuals $1.5-3 \mathrm{~m}$ tall. Furthermore, despite the effective dispersal of seeds, no self-seeded young plants have been observed in the surrounding areas after 15 years of experience. Additionally, it has been suggested that seedlings from small seeds may be more vulnerable to herbivores than those from large seeds, which clearly have greater uncommitted reserves available to compensate for various hazards, for example herbivory (Leishman et al., 2000). Therefore, the joint effect of herbivory by introduced mammals and the fact that only $50 \%$ of large seeds are legitimately dispersed may explain the common recruitment of $D$. draco in urban gardens and some rural areas where vertebrate herbivores are nowadays scarce or absent. These factors, in combination with others (e.g., climate change and habitat disappearance, livestock grazing and agriculture through nearly two thousand years since pre-Hispanic settlements), would be the main cause of disappearance of wild Canary dragon tree groves. This is already beginning to happen with the extant dragon tree populations (D. cinnabari) on Socotra (Attorre et al., 2007; Habrova et al., 2009). 


\section{CONCLUDING REMARKS AND FUTURE AVENUES}

Considering our results, the current vulnerable situation of $D$. draco as a ghost tree in the wild can be attributed to the synergistic effects of a partially eroded dispersal system and exposure to human exploitation and introduced herbivores. The probability of legitimate dispersal is inverse to the seed size and it strongly depends on the medium-size passerine T. merula and possibly on the pigeon $C$. junoniae, at least in the past, when both the plant and the pigeon were more abundant. Moreover, genetic drift in the widely separated relict wild populations might be acting as an additional vulnerability factor.

In future, to compare the functionality of the current dispersal system to that which could have existed in the past (likely including giant lizards), captivity-experimental studies would be necessary with endangered large-sized animals (mainly pigeons and giant lizards) to assess their level of frugivory on $D$. draco fruits and the consequences of their gut treatment on seeds, comparing it with the current dispersers. Also, further studies should explicitly address the net effect of introduced herbivores on the natural regeneration of this plant species. Lastly, it will be necessary to understand if the low quality of fruits and seeds produced by some individuals results from genetic drift and/or pollination limitations caused by the current small size and highly fragmented status of wild $D$. draco populations. These considerations must be taken into account to guide future studies and conservation actions on this iconic tree waiting to be revived from its present ghost status.

\section{DATA AVAILABILITY}

The datasets analyzed for this study can be found in the figshare repository at doi: 10.6084/m9.figshare.c.4395602.v1.

\section{ETHICS STATEMENT}

The fieldwork on Gran Canaria was carried out with permission provided by its Island Government (Cabildo de Gran Canaria). No pigeons used for the captivity experiment were harmed and procedures were according to the World Medical Assembly's Declaration of Helsinski of 1964 on human and animal rights, as

\section{REFERENCES}

Attorre, F., Francesconi, F., Taleb, N., Scholte, P., Saed, A., Alfo, M., et al. (2007). Will dragonblood survive the next period of climate change? Current and future potential distribution of Dracaena cinnabari (Socotra, Yemen). Biol. Conserv. 138, 430-439. doi: 10.1016/j.biocon.2007.05.009

Carlo, T. A., Aukema, J. E., and Morales, J. M. (2007). "Plant-frugivory interactions as spatially explicit networks: integrating frugivore foraging with fruiting plant spatial patterns," in Seed Dispersal: Theory and its Application in a Changing World, eds. A. J. Dennis, E. W. Schupp, R. J. Green and D. A. Westcott (Wallingford: CAB International), 369-390.

Clark, J. S., Silman, M., Kern, R., Macklin, E., and HilleRisLambers, J. (1999). Seed dispersal near and far: patterns across temperate and tropical forests. Ecology 80, 1475-1494. doi: 10.1890/0012-9658(1999)080[1475:SDNAFP]2.0.CO;2

Connell, J. H. (1971). "On the role of natural enemies in preventing competitive exclusion in some marine animals and in rain forest trees," in Dynamics of well as the guidelines proposed by the Association for the Study of Animal Behavior. The captivity experiments were carried out with permission from the Cabildo de Gran Canaria and following the biosecurity protocols for management of captive birds "Plan de Confinamiento y de Bioseguridad de las aves de corral y otras aves cautivas" published by the Ministerio de Agricultura y Pesca, Alimentación y Medio Ambiente (Spanish Government).

\section{AUTHOR CONTRIBUTIONS}

AG-C and MN conceived the idea. AG-C, DP-P, and JR performed the observational and experimental work. AG-C and DP-P performed statistical analyses. AG-C led the manuscript writing. JR significantly contributed to manuscript improvement. All authors revised manuscript drafts.

\section{FUNDING}

Frugivory data on Gran Canaria were taken by AG-C during his doctoral fellowship (JAE-PRE from the Spanish National Research Council, CSIC). The fieldwork was financed by a project from The Spanish Ministry of Science and Education (CGL2007-61165/BOS), supported by FEDER funds from the European Union. AG-C is currently funded by the Cabildo de Tenerife, under the identification mark Tenerife 2030 (Program TF INNOVA 2016-2021) with MEDI and FDCAN funds. Pigeon feeding trials were carried out at the Cabildo de Gran Canaria's facilities funded by the LIFE+ Rabiche program (LIFE12 NAT/ES/000354).

\section{ACKNOWLEDGMENTS}

The company Tagoro Medioambiente provided its greenhouse and access to its dragon tree plantations, to perform the seedling emergence experiments and frugivory censuses. The Cabildo de Gran Canaria provided AG-C with the necessary permissions to perform the fieldwork during his Ph.D. Thesis. We are especially grateful to Manuel Martín for his valuable help in the seedling emergence experiments, to Aurelio Martín for sharing his background knowledge of Canary Islands endemic pigeons, and to Alfredo Valido regarding the information about interactions. Guido Jones revised the English of this manuscript.

Populations, eds. P. J. Den Boer and G. Gradwell (Wageningen: PUDOC), 298-312.

Cordeiro, N. J., and Howe, H. F. (2002). Low recruitment of trees dispersed by animals in African forest fragments. Conserv. Biol. 15, 1733-1741. doi: 10.1046/j.1523-1739.2001.99579.x

Culliney, S., Pejchar, L., Switzer, R., and Ruiz-Gutierrez, V. (2012). Seed dispersal by a captive corvid: the role of the 'Alala (Corvus hawaiiensis) in shaping Hawai'i's plant communities. Ecol. Appl. 22, 1718-1732. doi: 10.1890/11-1613.1

Fenner, M., and Thompson, K. (2005). The Ecology of Seeds. Cambridge, UK: Cambridge University Press.

Fernández-Palacios, J. M., Otto, R., Delgado, J. D., Arévalo, J. R., Naranjo, A., González Artiles, F., et al. (2008). Los Bosques Termófilos de Canarias. Proyecto LIFE04/NAT/ES/000064. Excmo. Cabildo Insular de Tenerife, Santa Cruz de Tenerife.

Forget, P. M., and Milleron, T. (1991). Evidence for secondary seed dispersal by rodents in Panama. Oecologia 87, 596-599. doi: 10.1007/BF00320426 
Galetti, M., Guevara, R., Côrtes, M. C., Fadini, R., Von Matter, S., Leite, A. B., et al. (2013). Functional extinction of birds drives rapid evolutionary changes in seed size. Science 340, 1086-1090. doi: 10.1126/science.1233774

Gilpin, M. (1991). The genetic effective size of a metapopulation. Biol. J. Linn. Soc. 42, 165-175. doi: 10.1111/j.1095-8312.1991.tb00558.x

González-Castro, A., Traveset, A., and Nogales, M. (2012). Seed dispersal interactions in the mediterranean region: contrasting patterns between islands and mainland. J. Biogeogr. 39, 1938-1947. doi: 10.1111/j.1365-2699.2012.02693.x

Guimarães, Jr. P. R., Galetti, M., and Jordano, P. (2008). Seed dispersal anachronisms: rethinking the fruits extinct megafauna ate. PLoS ONE 3:e1745. doi: 10.1371/journal.pone.0001745

Habrova, H., Cermak, Z., and Pavlis, J. (2009). Dragon's blood tree-threatened by overmaturity, not by extinction: dynamics of a Dracaena cinnabari woodland in the mountains of Soqotra. Biol. Conserv. 142, 772-778. doi: 10.1016/j.biocon.2008.12.022

Hansen, D. M., and Galetti, M. (2009). The forgotten Megafauna. Science 324, 42-43. doi: 10.1126/science. 1172393

Herrera, C. M. (1995). Plant-vertebrate seed dispersal systems in the Mediterranean: ecological, evolutionary and historical determinants. Annu. Rev. Ecol. Syst. 26, 705-727. doi: 10.1146/annurev.es.26.110195.003421

IUCN (2018). IUCN Red List of Threatened Species. Version 2018.1. Available online at: http://www.iucnredlist.org

Janzen, D. H. (1970). Herbivores and the number of tree species in tropical forests. Am. Nat. 104, 501-529. doi: 10.1086/282687

Jordano, P., and Schupp, E. W. (2000). Seed disperser effectiveness: the quantity component and patterns of seed rain for Prunus mahaleb. Ecol. Monogr. 70, 591-615. doi: 10.2307/2657187

Leishman, M. R., Wright, I. J., Moles, A. T., and Westoby, M. (2000). "The evolutionary ecology of seed size," in Seeds: The Ecology of Regeneration in Plant Communities, eds. M. Fenner (Wallingford: CABI Publication), 31-57.

Marrero, A., Almeida Pérez, R., and González Martín, M. (1998). A new species of the wild dragon tree, Dracaena (Dracaenaceae) from Gran Canaria and its taxonomic and biogeographic implications. Bot. J. Linn. Soc. 128, 291-314.

Marrero, A., and Pérez, R. A. (2012). A new subspecies, Dracaena draco (L.) L. subsp. caboverdeana Marrero Rodr. and R. Almeida (Dracaenaceae) from Cape Verde Islands. Int. J. Geobot. Res. 2, 35-40. doi: 10.5616/ijgr120004

Marrero, P. (2009). Ecología trófica de las palomas endémicas de las Islas Canarias. Ph.D. Thesis, Universidad de La Laguna.

Marrero, P., Padilla, D. P., Valdés, F., and Nogales, M. (2007). Comparison of three Chemicals test to assess seed viability: the seed dispersal system of the Macaronesian endemic plant Rubia fruticosa (Rubiaceae) as an example. Chemoecology 17, 47-50. doi: 10.1007/s00049-006-0360-x

Martín, A., Hernández, M. A., Lorenzo, J. A., Nogales, M., and González, C. (2000). Las Palomas Endémicas de Canarias. Viceconsejería de Medio ambiente del Gobierno de Canarias y SEO/BirdLife, Santa Cruz de Tenerife.

McConkey, K. R., and Drake, D. R. (2006). Flying foxes cease to function as seed dispersers long before they become rare. Ecology, 87, 271-276. doi: 10.1890/05-0386

McConkey, K. R., and O'Farrill, G. (2016). Loss of seed dispersal before the loss of seed dispersers. Biol. Conserv. 201, 38-49. doi: 10.1016/j.biocon.2016.06.024

Muñoz, A., and Bonal, R. (2011). Linking the seed dispersal to cache protection strategies. J. Ecol. 99, 1016-1025. doi: 10.1111/j.1365-2745.2011.01818.x

Nathan, R. (2006). Long-distance dispersal of plants. Science 313, 786-788. doi: 10.1126/science.1124975

Nathan, R., and Muller-Landau, H. C. (2000). Spatial patterns of seed dispersal, their determinants and consequences for recruitment. Trends Ecol. Evol. 15, 278-285. doi: 10.1016/S0169-5347(00)01874-7

Nyiramana, A., Mendoza, I., Kaplin, B. A., and Forget, P. M. (2011). Evidence for seed dispersal by rodents in tropical montane forest in Africa. Biotropica 43, 654-657. doi: 10.1111/j.1744-7429.2011.00810.x

Pérez-Méndez, N., Jordano, P., and Valido, A. (2015). Downsized mutualisms: consequences of seed dispersers' body-size reduction for early plant recruitment. Perspect. Plant Ecol. Evol. Syst. 17, 151-159. doi: 10.1016/j.ppees.2014.12.001

Pérez-Méndez, N., Jordano, P., and Valido, A. (2018). Persisting in defaunated landscapes: reduced plant population connectivity after seed dispersal collapse. J. Ecol. 106, 936-947. doi: 10.1111/1365-2745.12848
Rey, P. J., Gutiérrez, J. E., Alcántara, J., and Valera, F. (1997). Fruit size in wild olives: implications for avian seed dispersal. Funct. Ecol. 11, 611-618. doi: 10.1046/j.1365-2435.1997.00132.x

Roach, D. A., and Wulff, R. D. (1987). Maternal effects in plants. Ann. Rev. Ecol. Evol. Syst. 18, 209-235. doi: 10.1146/annurev.es.18.110187. 001233

Robertson, A. W., Trass, A., Ladley, J. J., and Kelly, D. (2006). Assessing the benefits of frugivory for seed germination: the importance of deinhibition effect. Funct. Ecol. 20, 58-66. doi: 10.1111/j.1365-2435.2005.01057.x

Russo, S. E., and Augspurger, C. K. (2004). Aggregated seed dispersal by spider monkeys limits recruitment to clumped patterns in Virola calophylla. Ecol. Lett. 7, 1058-1067. doi: 10.1111/j.1461-0248.2004.00668.x

Samuels, I. A., and Levey, D. J. (2005). Effects of gut passage on seed germination: do experiments answer the questions they ask? Funct. Ecol. 19, 365-368. doi: 10.1111/j.1365-2435.2005.00973.x

Santos, A. (1979). Árboles de Canarias. Editorial Interinsular Canaria SA, Santa Cruz de Tenerife.

Säterberg, T., Stellman, S., and Ebenman, B. (2013). High frequency of functional extinctions in ecological networks. Nature 499, 468-470. doi: 10.1038/nature12277

Schleuning, M., Böhning-Gaese, K., Dehling, D. M., and Burns, K. C. (2014). At a loss for birds: insularity increases asymmetry in seed-dispersal networks. Glob. Ecol. Biogeogr. 23, 385-394. doi: 10.1111/geb.12134

Sekercioglu, C. H., Daily, G. C., and Ehrlich, P. R. (2004). Ecosystem consequences of bird declines. Proc. Natl. Acad. Sci. U.S.A. 101, 18042-18047. doi: 10.1073/pnas.0408049101

Sokal, R. R., and Rohlf, F. J. (1995). Biometry, 3rd Edn. New York, NY: Freeman.

Tilman, D., May, R. M., Lehman, C. L., and Nowak, M. A. (1994). Habitat destruction and the extinction debt. Nature 371, 65-66. doi: 10.1038/37 $1065 \mathrm{a} 0$

Traveset, A., and Riera, N. (2005). Disruption of a plant-lizard seed dispersal system and its ecological effects on a threatened endemic plant in the Balearic Islands. Conserv. Biol. 19, 422-431. doi: 10.1111/j.1523-1739.2005. 00019.x

Tylianakis, J. M., Didham, R. K., Bascompte, J., and Wardle, D. A. (2008). Global change and species interactions in terrestrial ecosystems. Ecol. Lett. 11, 1351-1363. doi: 10.1111/j.1461-0248.2008. 01250.x

Valido, A. (1999). Ecología de la Dispersión de Semillas por Lagartos Endémicos Canarios (g. Gallotia, Lacertidae). Ph.D. Thesis, Departamento de Biología Animal (Zoología). Universidad de La Laguna.

Wenny, D. G. (2001). Advantages of seed dispersal: a re-evaluation of directed dispersal. Evol. Ecol. Res. 3, 51-74. https://pdfs.semanticscholar.org/6442/ b39ee02e2cf56acfe8f514a4bc6b69d84bf9.pdf?_ga=2.125406605.662124772. 1549794733-627044681.1549794733

Wheelwright, N. T. (1985). Fruit size, gape width, and the diets of fruit-eating birds. Ecology 66, 808-818. doi: 10.2307/1940542

Wilcock, C., and Neiland, R. (2002). Pollination failure in plants: why it happens and when it matters. Trends Plant Sci. 7, 270-277. doi: 10.1016/S1360-1385(02)02258-6

Wotton, D. M., and Kelly, D. (2011). Frugivore loss limits recruitment of largeseeded trees. Proc. R. Soc. Biol. Sci. 278, 3345-3354. doi: 10.1098/rspb.2011. 0185

Conflict of Interest Statement: The authors declare that the research was conducted in the absence of any commercial or financial relationships that could be construed as a potential conflict of interest.

The reviewer, KM, declared her involvement in a large collaboration with two of the authors, AG-C and MN, to the handling editor.

Copyright (C) 2019 González-Castro, Pérez-Pérez, Romero and Nogales. This is an open-access article distributed under the terms of the Creative Commons Attribution License (CC BY). The use, distribution or reproduction in other forums is permitted, provided the original author(s) and the copyright owner(s) are credited and that the original publication in this journal is cited, in accordance with accepted academic practice. No use, distribution or reproduction is permitted which does not comply with these terms. 